\title{
PROCESSO DE BRINCAR DA CRIANÇA HOSPITALIZADA GUIADO PELO MODELO LÚDICO*
}

Dayane Regina dos Santos¹, Carmem Maria Sales Bonfim², Verônica de Azevedo Mazza3, Marilene Loewen Wall3, Nen Nalú Alves das Mercês ${ }^{3}$

1Terapeuta ocupacional. Mestre em Enfermagem. Universidade Federal do Paraná. Curitiba-PR-Brasil.

${ }^{2}$ Médica. Especialista em Transplante de Células Tronco Hematopoiéticas. Universidade Federal do Paraná. Curitiba-PR-Brasil.

${ }^{3}$ Enfermeira. Doutora em Enfermagem. Universidade Federal do Paraná. Curitiba-PR-Brasil.

RESUMO: O brincar é fundamental para o desenvolvimento saudável da criança e durante a hospitalização pode configurar-se como estratégia de cuidado, desde que sua aplicação seja sistematizada e fundamentada. O objetivo do estudo é relatar o processo de brincar guiado pelo Modelo Lúdico. Os participantes foram três crianças do sexo masculino, hospitalizadas em um serviço de transplante de medula óssea, entre setembro e outubro de 2012. A coleta dos dados se deu por meio de instrumentos adaptados do Modelo Lúdico e se desenvolveu em três etapas: conhecendo a criança, cuidando e brincando e acompanhando a evolução do comportamento lúdico. As crianças foram participativas, demonstrando autonomia, prazer e manutenção do papel ocupacional. O Modelo Lúdico foi considerado importante ferramenta para nortear o cuidado integral e humanizado nesse contexto.

DESCRITORES: Ludoterapia; Jogos e brinquedos; Criança hospitalizada; Cuidado da criança.

\section{THE PLAY PROCESS OF THE HOSPITALIZED CHILD, GUIDED BY THE LUDIC MODEL}

\begin{abstract}
Playing is fundamental for the healthy development of the child, and during hospitalization can be configured as a care strategy, as long as it is applied systematically and grounded in theory. This study's objective is to report the play process guided by the Ludic Model. The participants were three male children, receiving inpatient treatment in a bone marrow transplantation service, between September and October 2012. Data collection occurred through instruments adapted from the Ludic Model, and progressed in three stages: getting to know the child, caring and playing, and accompanying the evolution of the ludic behavior. The children were participative, demonstrating autonomy, pleasure, and maintenance of the occupational role. The Ludic Model was considered an important tool for guiding the comprehensive and humanized care in this context. DESCRIPTORS: Play therapy; Games and toys; Hospitalized child; Care of the child.
\end{abstract}

\section{PROCESO DE JUGAR DEL NIÑO HOSPITALIZADO DE ACUERDO CON EL MODELO LÚDICO}

RESUMEN: El jugar es fundamental para el desarrollo saludable del niño y durante la hospitalización puede configurarse como estrategia de cuidado, desde que su aplicación sea sistematizada y fundamentada. El objetivo del estudio fue relatar el proceso de jugar de acuerdo con el Modelo Lúdico. Los participantes fueron tres niños del sexo masculino, hospitalizados en un servicio de trasplante de médula, entre septiembre y octubre de 2012. Los datos fueron obtenidos por medio de instrumentos adaptados del Modelo Lúdico y eso se desarrolló en tres etapas: conociendo el niño, cuidando y jugando y acompañando la evolución del comportamiento lúdico. Los niños fueron participativos, demostrando autonomía, placer y manutención del papel ocupacional. El Modelo Lúdico fue considerado importante herramienta para nortear el cuidado integral y humanizado en ese contexto.

DESCRIPTORES: Ludoterapia; Juegos y juguetes; Niño hospitalizado; Cuidado del niño.

\footnotetext{
*Artigo originado da dissertação intitulada "Aplicabilidade do Modelo Lúdico no Processo Terapêutico Ocupacional de Cuidado da Criança em Transplante de Células-Tronco Hematopoiéticas" apresentada ao Programa de Pós-Graduação em Enfermagem da Universidade Federal do Paraná, 2013
}

Autor Correspondente:

Dayane Regina dos Santos

Universidade Federal do Paraná

Rua Brasílio Bacellar Filho, 451 82620-250 - Curitiba-PR-Brasil

E-mail: dayterapeuta@gmail.com
Recebido: $29 / 05 / 2014$ Finalizado: 18/08/2014 


\section{INTRODUÇÃO}

A infância é um período fundamental do desenvolvimento humano, no qual ocorre a aquisição de habilidades neuropsicomotoras e sociais. Um dos principais processos de aprendizado da criança é o brincar, por meio do qual explora o ambiente e a si mesma, desenvolve entendimento do mundo e interage com o mesmo ${ }^{(1)}$. Trata-se da atividade mais importante da infância e configura-se como o papel ocupacional da criança, contribuindo para o desenvolvimento de novas habilidades, capacidades e competências ${ }^{(2)}$.

Aspectos do ambiente podem facilitar ou impedir a disposição para brincar. Ambientes que se mostram amigáveis, seguros e confortáveis com variedade de objetos e atividades estimulam a criança a brincar ${ }^{(3)}$ e contribuem para o seu desenvolvimento saudável. O ambiente hospitalar é desconhecido e impessoal, com aparelhos estranhos e assustadores e a rotina é permeada por procedimentos que podem causar dor e desconforto, determinando atividades e horários diversos dos quais se está habituado ${ }^{(4)}$.

A criança submetida ao Transplante de Células-Tronco Hematopoéticas permanece um longo período no hospital, o que pode ser uma experiência traumática e geradora de sofrimentos. Estar doente e hospitalizada representa mudança drástica na vida cotidiana e essa condição desencadeia sentimentos como ansiedade, tristeza, solidão, insegurança e medo ${ }^{(5)}$. Assim, compreende-se que as características adversas do ambiente hospitalar, combinadas com a debilidade causada pela doença e/ou procedimentos, podem privar a criança de suas principais atividades ${ }^{(1)}$, prejudicando, assim, seu desenvolvimento ${ }^{(1,4)}$.

Nesse sentido, o brincar apresenta-se como estratégia de cuidado, auxiliando no enfrentamento da situação de hospitalização e humanizando a assistência à saúde da criança ${ }^{(4,6)}$. As brincadeiras proporcionam diversão e relaxamento, auxiliam a sentir-se mais segura em ambiente desconhecido, contribuem para a redução do estresse, favorecem a liberação e a expressão de sentimentos, e colocam a criança em uma função ativa, com oportunidades para fazer escolhas ${ }^{(7)}$. No entanto, para alcançar todos os benefícios do brincar é necessário que o mesmo seja promovido de maneira sistematizada, como parte de um plano de assistência de profissionais preparados para utilizá-lo como recurso terapêutico ${ }^{(1,6)}$.

O Modelo Lúdico é um referencial teórico que propõe a utilização sistemática do brincar, com o objetivo de auxiliar a criança a desenvolver capacidade de agir e atitude para enfrentar os desafios cotidianos. Esse apresenta um quadro de trabalho preciso sobre os planos teórico e clínico, com abordagem global e positiva da criança, por meio de um campo de atividades próprio a ela e possibilita a fundamentação da prática em dados científicos $^{(8)}$.

Nesse sentido, esse estudo tem como objetivo relatar o processo de brincar da criança submetida ao Transplante de Células-Tronco Hematopoéticas guiado pelo Modelo Lúdico.

\section{DESCRIÇÃO DA EXPERIÊNCIA}

Trata-se de um relato de experiência realizado no Serviço de Transplante de Medula Óssea do Hospital de Clínicas da Universidade Federal do Paraná, referência nacional em Transplante de Células-Tronco Hematopoéticas. O período de realização foi de setembro a outubro de 2012, tendo três crianças como participantes. Os critérios de inclusão foram: ter entre três e dez anos de idade, estar hospitalizado e aceitar participar da proposta, além da autorização do responsável legal mediante assinatura do Termo de Consentimento Livre e Esclarecido. O estudo foi aprovado pelo Comitê de Ética em Pesquisas com Seres Humanos da Instituição, sob o parecer n. 100.881/2012. O processo de brincar, guiado pelo Modelo Lúdico, seguiu as seguintes etapas: conhecendo a criança, cuidando e brincando, e acompanhando a evolução do comportamento lúdico ${ }^{(8)}$, descritas a seguir.

\section{Conhecendo a Criança}

Os participantes foram três crianças do sexo masculino: C1 (sete anos), C2 e C3 (ambos com nove anos). C1 e C2 com diagnóstico de Anemia de Fanconi e C3 de Leucemia Aguda de Linhagem Ambígua. C1 procedente de Itapuranga (GO), C2 de Várzea Grande (MT) e C3 de Foz do Iguaçu (PR). C1 e C2 foram acompanhados somente pelas mães durante o processo de TCTH e C2 foi acompanhado, também, pelo pai. 
Para conhecer o brincar de cada criança realizou-se um processo avaliativo com a utilização de dois instrumentos: Entrevista Inicial com os Pais sobre o Comportamento Lúdico da Criança e Avaliação do Comportamento Lúdico(8).

No primeiro instrumento obtiveram-se informações acerca do comportamento lúdico das crianças em casa. As entrevistas foram realizadas com as mães das crianças, em horário e local, previamente, agendados, cuja duração variou entre 26 e 42 minutos.

As mães mostraram-se receptivas, relatando as atividades preferidas de seus filhos, revelando o interesse em atividades lúdicas próprias para a faixa etária: bola, carrinho, super-heróis, jogos e videogame. Com relação à rotina, $\mathrm{C} 1$ frequentava a escola, C3 recebia aulas em casa e C2 deixou de estudar com o início dos sintomas da doença. As mães deixaram de trabalhar para cuidar dos filhos, devido à necessidade de acompanhamento médico contínuo e de frequentes transfusões de hemoderivados.

Ao final de cada entrevista foi agendado um horário para a avaliação individual da criança. A Avaliação do Comportamento Lúdico $^{(8)}$ determinou seus interesses, capacidades, atitude lúdica e a forma de expressão de necessidades e sentimentos, sendo realizada a partir da observação das crianças em um ambiente preparado com objetos e materiais que convidassem à brincadeira.

Os materiais disponibilizados foram: lápis e desenhos de personagens indicados pelas mães para colorir, bonecos e carrinhos (que permitem a brincadeira simbólica) e jogos (dominó, dama, pega-varetas e UNO).

A duração das avaliações variou entre 38 e 41 minutos. $\mathrm{C} 1$ e $\mathrm{C} 3$ estiveram comunicativos, com iniciativa para explorar os materiais e iniciar uma situação de brincadeira. C2 mostrou-se reservado e silencioso, embora atento às falas e ações da pesquisadora, contudo necessitou de estímulos para brincar, confirmando o que fora relatado pela mãe durante a entrevista: considera o filho tímido.

Ao final das avaliações as crianças podiam ficar com os materiais ou escolher aqueles pelos quais tinham maior interesse. Os três optaram por ficar com todos, combinando que seriam devolvidos no momento da alta hospitalar.

\section{Cuidando e Brincando}

Com base nas avaliações os objetivos terapêuticos traçados foram: manter a atitude e a ação lúdica de C1 e C3 e estimular a iniciativa de C2 para a brincadeira, além de promover oportunidades para a expressão e comunicação. O objetivo principal do Modelo Lúdico nesta fase foi descobrir ou manter o prazer da ação de brincar, mesmo em um ambiente adverso ${ }^{(8)}$, como o hospital. Os materiais e brinquedos utilizados eram passíveis de desinfecção, de acordo com as normas da instituição. Tais cuidados são imperativos para a prevenção do agravo das condições clínicas das crianças, que se encontravam imunodeprimidas e vulneráveis a diversas infecções.

Com estas premissas a pesquisadora encontrou cada criança, individualmente, em seu respectivo quarto, três vezes por semana, entre 40 e 60 minutos, durante todo o período de hospitalização que variou de 29 a 31 dias. Não foi possível atender $\mathrm{C} 1 \mathrm{em}$ duas ocasiões, pois se encontrava dormindo, devido à administração de medicação de preparo para a infusão de hemoderivados. C2 não quis brincar em dois dias, devido à sonolência secundária à administração de analgésicos, para o controle da dor intensa causada por mucosite.

As atividades realizadas durante os encontros foram: pintura, jogos diversos, quebra-cabeça, brincadeira simbólica com bonecos de personagens, animais e carrinhos. Os jogos foram as atividades mais solicitadas, durante as quais as crianças demonstravam prazer e satisfação, caracterizados por sorrisos, diversão e verbalizações.

Respeitando os princípios do Modelo Lúdico $^{(8)}$, cada criança tomou decisões e escolheu a brincadeira a ser realizada. A pesquisadora manifestou atitude lúdica, sendo espontânea, expressando prazer e propondo situações durante as atividades, fazendo com que a criança se sentisse mais à vontade para também adotar tal atitude.

\section{Acompanhando a evolução do comportamento lúdico}

O acompanhamento deu-se através da observação dos participantes durante as atividades 
lúdicas, com base no instrumento Evolução do Comportamento Lúdico: atitude e ação ${ }^{(8)}$. Adotouse, também, um diário de campo para o registro das percepções relacionadas aos dados não contemplados pelo instrumento.

C1 e C3 foram sempre participativos e comunicativos, demonstrando contentamento com a chegada da pesquisadora, a quem convidavam para realizar a atividade escolhida. O comportamento e a atitude lúdica foram mantidos, mesmo quando passavam pelas complicações esperadas, secundárias ao TCTH, como mucosite, náusea e vômito.

C2, embora mais reservado, demonstrava reconhecer a pesquisadora como uma parceira para a brincadeira, sorrindo timidamente à chegada da mesma. Nos dois primeiros encontros precisou de estímulos para iniciar uma situação de brincadeira, mesmo assim, as atividades realizadas foram de sua escolha. Gradualmente, mostrou-se mais autônomo, iniciando a atividade lúdica, comunicando-se mais e demonstrando maior prazer na ação de brincar.

A etapa de acompanhamento foi realizada, concomitantemente, à segunda etapa e auxiliou a planejar cada encontro pela análise das atitudes e ações envolvidas no brincar.

\section{CONSIDERAÇÕES FINAIS}

As crianças envolveram-se em atividades lúdicas utilizando os materiais deixados pela pesquisadora, mesmo em dias e horários em que a mesma não estava na unidade, confirmando que essa abordagem favorece a manutenção do papel ocupacional. Os objetivos terapêuticos traçados foram atingidos, sendo possível inserir o brincar no cotidiano das crianças durante o período de hospitalização.

O Modelo Lúdico mostrou-se uma importante ferramenta para sistematizar o brincar como estratégia de cuidado à criança hospitalizada, sendo esse um cuidado integral, centrado na criança e apoiado nos pressupostos da humanização. Estudos futuros são necessários para a adequação dos instrumentos às características do contexto hospitalar, mas, ressalta-se que os conceitos e linhas gerais desse referencial metodológico são perfeitamente aplicáveis ao cuidado da clientela pediátrica assistida nesse espaço.

\section{REFERÊNCIAS}

1. Santos CA, Marques EM, Pfeifer LI. A brinquedoteca sob a visão da terapia ocupacional: diferentes contextos. Cad. Ter. Ocup. UFSCar. [Internet] 2006;14(2) [acesso em 14 mai 2014]. Disponível: http:// www.cadernosdeterapiaocupacional.ufscar.br/index. php/cadernos/article/viewFile/158/114

2. Pfeifer LI, Rombe PG, Santos JLC. A influência socioeconômica e cultural no brincar de pré-escolares. Paideia. [Internet] 2009;19(43) [acesso em 14 mai 2014]. Disponível: http://dx.doi.org/10.1590/S0103863X2009000200013

3. Primeau LA. Play and leisure. In: Crepeau EB, Cohn ES, Schell BAB (editors). Willard \&Spackman's occupational therapy. Philadelphia: Lippincott William \& Wilkins; 2009.p. 633-47.

4. Gomes CG, Nicola GDO, Souza NZ, Chagas MCS, Farias DFR, Xavier DM. Percepções da família acerca das dificuldades de adaptação da criança à hospitalização: subsídios para a enfermagem. Cogitare enferm. [Internet] 2013;18(4) [acesso em 15 mai 2014]. Disponível: http://ojs.c3sl.ufpr.br/ojs2/index.php/ cogitare/article/view/34935/21687

5. Gomes ILV, Queiroz MVO, Bezerra LLA, Souza NPG. A hospitalização no olhar de crianças e adolescentes: sentimentos e experiências vivenciadas. Cogitare enferm [Internet] 2012;17(4) [acesso em 15 mai 2014]. Disponível: http://ojs.c3sl.ufpr.br/ojs2/index.php/ cogitare/article/view/30378/19654

6. Nascimento CN, Pedro ICS, Poleti LC, Borges ALV, Pfeifer LI, Lima RAG. O brincar em sala de espera de um ambulatório infantil: a visão dos profissionais de saúde. Rev Esc Enferm USP. [Internet] 2011;45(2) [acesso em 14 mai 2014]. Disponível: http://dx.doi. org/10.1590/S0080-62342011000200023

7. Castro DP, Andrade CUB, Luiz E, Mendes M, Barbosa D, Santos LHG. Brincar como instrumento terapêutico. Pediatria. [Internet] 2010;32(4) [acesso em 15 mai 2014]. Disponível: http://www.pediatriasaopaulo.usp. br/upload/pdf/1360.pdf

8. Ferland F. O Modelo lúdico: o brincar, a criança com deficiência física e a Terapia Ocupacional. Trad. de Maria Madalena Moraes Sant'Anna. São Paulo: Roca; 2006. 